\title{
Second-order boundary-layer effects for the unsteady laminar incompressible three-dimensional stagnation-point flow
}

\author{
M. Kumari, Bangalore, India
}

\begin{abstract}
All the second-order boundary-layer effects on the unsteady laminar incompressible flow at the stagnation-point of a three-dimensional body for both nodal and saddle point regions have been studied. It has been assumed that the freestream velocity, wall temperature and mass transfer vary arbitrarily with time. The effect of the Prandtl number has been taken into account. The partial differential equations governing the flow have been derived for the first time and then solved numerically using an implicit finite-difference scheme. It is found that the unsteady free-stream velocity distributions, the nature of the stagnation point and the mass transfer strongly affect the skin friction and heat transfer whereas the effects of the Prandtl number and the variation of the wall temperature with time are only on the heat transfer. The skin friction due to the combined effects of first- and second-order boundary layers is less than the skin friction due to, the first-order boundary layers whereas the heat transfer has the opposite behaviour. Suction increases the skin friction and heat transfer but injection does the opposite.
\end{abstract}

Grenzschichteffekte zweiter Ordnung fuir laminare inkompressible dreidimensionale Staupunktströmung

Zusammenfassung. Es wurden Grenzschichteffekte zweiter Ordnung bei instationärer laminarer inkompressibler Strömung am Staupunkt eines dreidimensionalen Körpers, sowohl für knotenartige als auch für sattelförmige Bereiche studiert. Dabei wurde angenommen, daß die Freistrahlgeschwindigkeit, die Wandtemperatur und der Stoffübergang beliebig mit der Zeit variieren. Der Einfluß Prandtlzahl wurde mit in Betracht gezogen. Die partiellen Differentialgleichungen welche die Strömung beschreiben, wurden zum ersten Mal abgeleitet und dann numerisch gelöst, wobei ein implizites finites Differenzverfahren verwendet wurde.

Es wurde gefunden, daß die Verteilung der instationären Freistrahlgeschwindigkeit die Natur des Staupunktes und der Stofftransport die Wandreibung und den Wärmeübergang stark beeinflussen, während die Prandtl-Zahl und zeitlich veränderliche Wandtemperaturen sich nur auf den Wärmeübergang auswirken. Die Wandreibung infolge der kombinierten Einflüsse von Grenzschichten erster und zweiter Ordnung ist kleiner als diejenige infolge der Grenzschichten erster Ordnung, während der Wärmetransport umgekehrtes Verhalten zeigt. Eine Absaugung erhöht die Wandreibung und den Wärmeübergang Zublasen hat umgekehrte Wirkung.

\section{Introduction}

Prandtl's boundary-layer theory provides a relatively accurate description of simple flow situations. However, many flows that occur in modern technology possess characteristics that cannot be treated within the simple framework of the Prandtl approximation. It is necessary for these more complicated flows, to seek approximate solutions to the Navier-Stokes equations that are of higher accuracy than the classical or Prandtl approximation. This extension of classical boundary-layer theory is called higher-order boundary-layer theory. Prandtl's theory represents only the first approximation to the Navier-Stokes equations. The second-order correction to the Prandtl approximation can be formulated by taking into account the curvature effect due to the longitudinal and transverse curvatures of the body surface, displacement and vorticity effects due to the interaction of the boundary-layer with external flow.

The excellent reviews of the second-order boundary layers for steady two-dimensional and axisymmetric bodies have been given by Van Dyke [1] and Gersten and Gross [2]. The self-similar solution of the unsteady secondorder two-dimensional and axisymmetric boundary layers for incompressible and compressible fluids has been obtained by Afzal and Rizvi [3], Arunachalam and Rajappa [4], Vasantha [5] and Vasantha and Nath [6]. The steady laminar incompressible and compressible three-dimensional stagnation-point second-order boundary-layer flows with or without mass transfer for nodal point of attachment have been investigated by Papenfuss [7-11], Gersten et al. [12] and Dwoyer et al. [13]. The steady three-dimensional stagnation-point second-order boundary layers for incompressible and compressible fluids for large mass transfer rates for both nodal and saddle points of attachments have been investigated by Vasantha [5], Krishnaswamy [14] and Krishnaswamy and Nath [15]. Recently, Kumari [16] has obtained the self-similar solution of the unsteady laminar incompressible three-dimensional stagnation-point second-order boundary layers 
for both nodal and saddle points of attachments. It may be remarked that the unsteady three-dimensional stagnationpoint second-order boundary-layer flow when the freestream varies arbitrarily with time has not been studied so far.

We have studied the unsteady laminar incompressible three-dimensional second-order boundary-layer flow for nodal and saddle point regions when the free-stream velocity, mass transfer and wall temperature vary arbitrarily with time. The effect of the Prandtl number has also been taken into account. The partial differential equations governing the flow have been obtained for the first time and subsequently were solved numerically using an implicit finite-difference scheme. The steady-state results have been compared with those obtained by Vasantha [5] and Papenfuss [7].

\section{Governing equations}

We consider the unsteady laminar incompressible boundary-layer flow in the stagnation region of a three-dimensional body when the velocity of the free-stream varies arbitrarily with time. It is assumed that the body has two planes of symmetry and the principal axes of the flow at the stagnation-point coincide with the directions of the principal curvature of the body (Fig. 1). The first- and second-order boundary-layer equations for three-dimensional flows can be obtained from the Navier-Stokes equations by using the method of matched asymptotic expansion. The detailed derivations of the first- and second-order boundary-layer equations are given in $[5,7,8]$, we omit the details here and present the governing equations with boundary conditions in final form as:

First-order equations

$$
\begin{gathered}
f^{\prime \prime \prime}+\varphi(f+c g) f^{\prime \prime}+\varphi\left(1-f^{2}\right) \\
+\varphi^{-1} \varphi_{t^{*}}\left(1-f^{\prime}\right)-f_{t^{*}}^{\prime}=0, \\
g^{\prime \prime \prime}+\varphi(f+c g) g^{\prime \prime}+\varphi c\left(1-g^{\prime 2}\right) \\
\quad+\varphi^{-1} \varphi_{t^{*}}\left(1-g^{\prime}\right)-g_{t^{*}}^{\prime}=0, \\
\theta^{\prime \prime}+\varphi \operatorname{Pr}(f+c g) \theta^{\prime}-\operatorname{Pr} \theta_{t^{*}}=0 .
\end{gathered}
$$

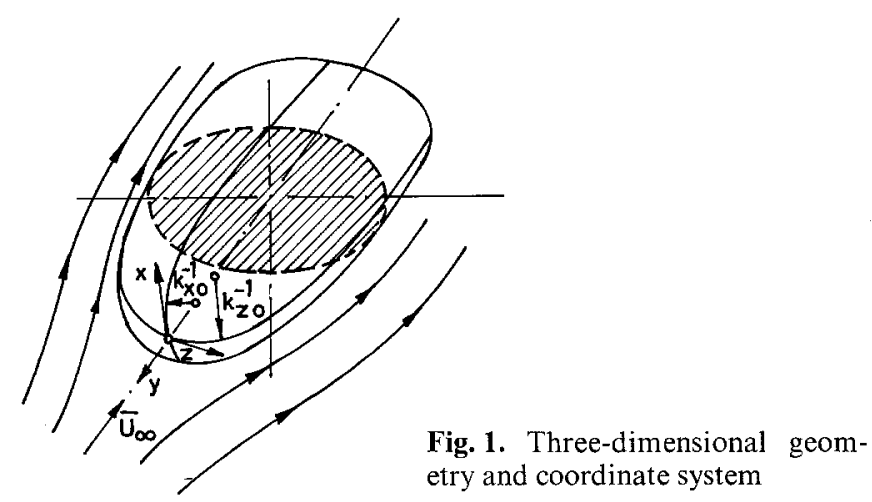

The boundary conditions are

$\left.\begin{array}{l}f=f_{w^{\prime}} f^{\prime}=g=g^{\prime}=0, \quad \theta=1-\varphi_{1}\left(t^{*}\right) \text { at } \eta=0 \\ f^{\prime} \rightarrow 1, \quad g^{\prime} \rightarrow 1, \quad \theta \rightarrow 1, \quad \text { as } \eta \rightarrow \infty\end{array}\right\}$

for $t^{*} \geqq 0$.

Second-order equations

(i) Longitudinal curvature

$D_{1}\left(F_{L}, G_{L}\right)=-\eta f^{\prime \prime \prime}+\varphi$

$$
\begin{aligned}
& {\left[(1-c) \eta+c \int_{0}^{\eta}\left(1-f^{\prime} g^{\prime}\right) d \eta+\alpha+c \beta-c \chi\right] } \\
&+\varphi^{-1} \varphi_{t^{*}}\left[\eta-\alpha-f+\eta f^{\prime}\right]+\alpha_{1}+\eta f_{t^{*}}^{\prime}-f_{t^{*}}, \\
& D_{2}\left(F_{L}, G_{L}\right)=-\eta g^{\prime \prime \prime}+\left[g^{\prime \prime}+\varphi(f+c g) g^{\prime}-\varphi 2 c \eta\right] \\
&+\varphi^{-1} \varphi_{t^{*}} \eta\left[g^{\prime}-2\right]+\eta g_{t^{*}}^{\prime}, \\
& D_{3}\left(H_{L}\right)=\theta^{\prime}\left\{\varphi \operatorname{Pr}\left[\eta(f+c g)-\left(F_{L}+c G_{L}\right)\right]-1\right\} .
\end{aligned}
$$

Boundary conditions

$$
\begin{aligned}
& F_{L}=F_{L}^{\prime}=G_{L}=G_{L}^{\prime}=H_{L}=0 \text { at } \eta=0 \\
& F_{L}^{\prime} \rightarrow-\eta_{\infty}, \quad G_{L}^{\prime} \rightarrow \eta_{\infty}, \quad H_{L} \rightarrow 0, \quad \text { as } \eta \rightarrow \infty \\
& \text { for } t^{*} \geqq 0 .
\end{aligned}
$$

(ii) Transverse curvature

$$
\begin{aligned}
D_{1}\left(F_{t}, G_{t}\right)= & -\eta f^{\prime \prime \prime}+\left[f^{\prime \prime}+\varphi(f+c g) f^{\prime}-\varphi 2 \eta\right] \\
& +\varphi^{-1} \varphi_{t^{*}} \eta\left[f^{\prime}-2\right]+\eta f_{t^{*}}^{\prime}, \\
D_{2}\left(F_{t}, G_{t}\right)= & -\eta g^{\prime \prime \prime}+\varphi \\
& {\left[(c-1) \eta+\int_{0}^{\eta}\left(1-f^{\prime} g^{\prime}\right) d \eta+\alpha+c \beta-\chi\right] } \\
& +\varphi^{-1} \varphi_{t^{*}}\left[\eta-\beta-g+\eta g^{\prime}\right]+\alpha_{2}+\eta g_{t^{*}}^{\prime}-g_{t^{*}},
\end{aligned}
$$

$D_{3}\left(H_{t}\right)=\theta^{\prime}\left\{\varphi \operatorname{Pr}\left[\eta(f+c g)-\left(F_{t}+c G_{t}\right)\right]-1\right\}$.

Boundary conditions

$$
\begin{aligned}
& F_{t}=F_{t}^{\prime}=G_{t}=G_{t}^{\prime}=H_{t}=0 \text { at } \eta=0
\end{aligned}
$$

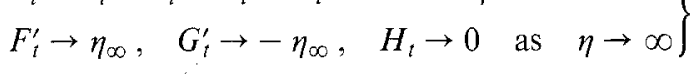

$$
\begin{aligned}
& \text { for } t^{*} \geqq 0 \text {. }
\end{aligned}
$$

(iii) Boundary-layer displacement (terms $\sim U_{21}$ )

$$
\begin{aligned}
& D_{1}\left(F_{d}, G_{d}\right)=-2 \varphi-\varphi^{-1} \varphi_{t^{*}}, \\
& D_{2}\left(F_{d}, G_{d}\right)=0, \\
& D_{3}\left(H_{d}\right)=-\varphi \theta^{\prime} \operatorname{Pr}\left(F_{d}+c G_{d}\right) .
\end{aligned}
$$

Boundary conditions

$$
\begin{aligned}
& F_{d}=F_{d}^{\prime}=G_{d}=G_{d}^{\prime}=H_{d}=0 \text { at } \eta=0, \\
& F_{d}^{\prime} \rightarrow 1, \quad G_{d}^{\prime} \rightarrow 0, \quad H_{d} \rightarrow 0 \text { as } \begin{array}{r}
\eta \rightarrow \infty, \\
\text { for } t^{*} \geqq 0 .
\end{array}
\end{aligned}
$$


iv) Boundary-layer displacement (terms $\left.\sim W_{21}\right)$

$$
\begin{aligned}
& D_{1}\left(F_{D}, G_{D}\right)=0, \\
& D_{2}\left(F_{D}, G_{D}\right)=-2 \varphi-\varphi^{-1} \varphi_{t^{*}} / c, \\
& D_{3}\left(H_{D}\right)=-\varphi \theta^{\prime} \operatorname{Pr}\left(F_{D}+c G_{D}\right) .
\end{aligned}
$$

Boundary conditions

$$
\begin{array}{r}
F_{D}=F_{D}^{\prime}=G_{D}=G_{D}^{\prime}=H_{D}=0 \text { at } \eta=0, \\
F_{D}^{\prime} \rightarrow 0, \quad G_{D}^{\prime} \rightarrow 1 / c, \quad H_{D} \rightarrow 0 \text { as } \eta \rightarrow \infty, \\
\text { for } t^{*} \geqq 0 .
\end{array}
$$

(v) Vorticity interaction (terms $\sim \Omega_{z 1}$ )

$$
\begin{aligned}
& D_{1}\left(F_{r}, G_{r}\right)=\varphi(\alpha+c \beta), \\
& D_{2}\left(F_{v}, G_{r}\right)=0, \\
& D_{3}\left(H_{l}\right)=-\varphi \theta^{\prime} \operatorname{Pr}\left(F_{r}+c G_{r}\right) .
\end{aligned}
$$

Boundary conditions

$$
\left.\begin{array}{r}
F_{r}=F_{r}^{\prime}=G_{r}=G_{r}^{\prime}=H_{l}=0 \quad \text { at } \eta=0, \\
F_{r}^{\prime} \rightarrow-\eta_{\infty} / \varphi, \quad G_{v}^{\prime} \rightarrow 0, \quad H_{r} \rightarrow 0 \text { as } \eta \rightarrow \infty, \\
\text { for } t^{*} \geqq 0 .
\end{array}\right\}
$$

(vi) Vorticity interaction (terms $\sim \Omega_{x 1}$ )

$$
\begin{aligned}
& D_{1}\left(F_{V}, G_{V}\right)=0, \\
& D_{2}\left(F_{V}, G_{V}\right)=\varphi(\alpha+c \beta), \\
& D_{3}\left(H_{V}\right)=-\varphi \theta^{\prime} \operatorname{Pr}\left(F_{V}+c G_{V}\right) .
\end{aligned}
$$

Boundary conditions

$$
\left.\begin{array}{c}
F_{V}=F_{V}^{\prime}=G_{V}=G_{V}^{\prime}=H_{V}=0 \quad \text { at } \quad \eta=0, \\
F_{V}^{\prime} \rightarrow 0, \quad G_{V}^{\prime} \rightarrow-\eta_{\infty} / \varphi c, \quad H_{V} \rightarrow 0 \text { as } \eta \rightarrow \infty, \\
\text { for } t^{*} \geqq 0 .
\end{array}\right\}
$$

The initial conditions for both first and second order boundary layer equations are given by the steady-state equations $\left(t^{*}=0\right)$ obtained by putting $t^{*}=0, \varphi=\varphi_{1}=1$, ()$_{t^{*}}=0$ in Eqs. (1)-(14).

Here

$$
\begin{aligned}
\eta & =k_{x 0} y U_{11}^{1 / 2} R e^{1 / 2}, \quad t^{*}=U_{\infty} k_{x 0} U_{11} t, \\
\operatorname{Re} & =\left(U_{\infty} \varrho\right) /\left(k_{x 0} \mu\right), \quad k=k_{z 0} / k_{x 0}, \quad c=W_{11} / U_{11},
\end{aligned}
$$

$$
\begin{aligned}
& u / U_{\infty}=U_{11} k_{x 0} x \varphi\left\{f^{\prime}+\varepsilon U_{11}^{-1 / 2}\left[F_{L}^{\prime}+k\left(F_{t}^{\prime}-\eta f^{\prime}\right)\right]\right. \\
& \left.+\varepsilon U_{11}^{-1}\left[U_{21} F_{d}^{\prime}+W_{21} F_{D}^{\prime}\right]+\varepsilon U_{11}^{-3 / 2}\left[\Omega_{z 1} F_{r}^{\prime}+\Omega_{x 1} F_{V}^{\prime}\right]\right\}
\end{aligned}
$$

$$
\begin{aligned}
v / U_{\infty}=-\varepsilon U_{11}^{1 / 2} \varphi\left\{[f+c g]+\varepsilon U_{11}^{-1 / 2}\right. & \cdot\left[F_{L}+c G_{L}-\eta(f+c g)\right. \\
+ & \left.k\left(F_{t}+c G_{t}-\eta(f+c g)\right)\right]+\varepsilon U_{11}^{-1}\left[U_{21}\left(F_{d}+c G_{d}\right)\right. \\
+ & \left.W_{21}\left(F_{D}+c G_{D}\right)\right]+\varepsilon U_{11}^{-3 / 2} \\
& \left.\cdot\left[\Omega_{z 1}\left(F_{v}+c G_{v}\right)+\Omega_{x 1}\left(F_{V}+c G_{V}\right)\right]\right\} .
\end{aligned}
$$

$$
\begin{aligned}
& w / U_{\infty}=W_{11} k_{x 0} z \varphi\left\{g^{\prime}+\varepsilon U_{11}^{-1 / 2}\left[G_{L}^{\prime}-\eta g^{\prime}+k G_{t}^{\prime}\right]\right. \\
& \left.+\varepsilon U_{11}^{-1}\left[U_{21} G_{d}^{\prime}+W_{21} G_{D}^{\prime}\right]+\varepsilon U_{11}^{-3 / 2}\left[\Omega_{z 1} G_{v}^{\prime}+\Omega_{x 1} G_{V}^{\prime}\right]\right\},
\end{aligned}
$$

$$
\begin{aligned}
& \left(T-T_{w}\right) /\left(T_{\infty}-T_{w}\right)=\theta^{\prime}+\varepsilon U_{11}^{-1 / 2}\left[H_{L}+k H_{t}\right] \\
& +\varepsilon U_{11}^{-1}\left[U_{21} H_{d}+W_{21} H_{D}\right]+\varepsilon U_{11}^{-3 / 2}\left[\Omega_{z 1} H_{r^{r}}+\Omega_{x 1} H_{V}\right],
\end{aligned}
$$

$f_{w}=A / \varphi\left(t^{*}\right), \quad \bar{U}_{\infty}=U_{\infty} \varphi\left(t^{*}\right), \quad \varepsilon=R e^{-1 / 2}$.

The operators $D_{1}, D_{2}$ and $D_{3}$ are given by

$$
\begin{aligned}
D_{1}(F, G)= & F^{\prime \prime \prime}+\varphi(f+c g) F^{\prime \prime}-2 \varphi f^{\prime} F^{\prime}+\varphi f^{\prime \prime}(F+c G) \\
& -\varphi^{-1} \varphi_{t^{*}} F^{\prime}-F_{t^{*}}^{\prime}, \\
D_{2}(F, G)= & G^{\prime \prime \prime}+\varphi(f+c g) G^{\prime \prime}-2 \varphi c g^{\prime} G^{\prime} \\
& +\varphi g^{\prime \prime}(F+c G)-\varphi^{-1} \varphi_{t^{*}} G^{\prime}-G_{t^{*}}^{\prime}, \\
D_{3}(H)= & H^{\prime \prime}+\varphi \operatorname{Pr}(f+c g) H^{\prime}-\operatorname{Pr} H_{t^{*}},
\end{aligned}
$$

and the functions $\alpha, \beta, \chi, \alpha_{1}$ and $\alpha_{2}$ are defined as

$$
\begin{aligned}
& x=\lim _{\eta \rightarrow \infty}(\eta-f), \\
& \beta=\lim _{\eta \rightarrow \infty}(\eta-g), \\
& \chi=\int_{0}^{\infty}\left(1-f^{\prime} g^{\prime}\right) d \eta, \\
& \alpha_{1}=\lim _{\eta \rightarrow \infty} f_{t^{*}}, \\
& \alpha_{2}=\lim _{\eta \rightarrow \infty} g_{i^{*}} .
\end{aligned}
$$

Here $x, y$ and $z$ are the principal, normal and transverse directions, respectively; $u, v$ and $w$ are the dimensional velocity components in the $x, y$ and $z$ directions, respectively; $T$ is the temperature; $f$ and $g$ are the first-order dimensionless stream functions in the $x$ and $z$ directions, respectively; $f^{\prime}$ and $g^{\prime}$ are the first-order dimensionless velocity components in the $x$ and $z$ directions, respectively; $\theta$ is the first-order dimensionless temperature; $F$ and $G$ are the second-order dimensionless stream functions in the $x$ and $z$ directions, respectively; $F^{\prime}$ and $G^{\prime}$ are the second-order dimensionless velocity components in the $x$ and $z$ directions, respectively; $H$ is the second-order dimensionless temperature; $\eta$ is the independent variable; $t$ and $t^{*}$ are the dimensional and dimensionless times, respectively; $R e$ is the Reynolds number; $k_{x 0}$ and $k_{z 0}$ are the normal curvatures of the coordinate lines, measured in the $x$ and $z$ directions, respectively; $U_{11}$ and $W_{11}$ are the first-order potential flow velocity gradients in the $x$ and $z$ directions, respectively; $U_{21}$ and $W_{21}$ are the secondorder potential flow velocity gradients in the $x$ and $z$ directions, respectively; $U_{\infty}, \varrho, \mu$ and $T_{\infty}$ are the freestream velocity at $t^{*}=0$, density, coefficient of viscosity and free-stream temperature, respectively; $c$ is the ratio of the velocity gradients in the $z$ and $x$ directions $(c \geqq 0$ $(0 \leqq c \leqq 1)$ for nodal point of attachment and $c<0$ 
$(-1 \leqq c<0)$ for saddle point of attachment); $\operatorname{Pr}$ is the Prandtl number; $A$ is the surface mass transfer parameter ( $A<0$ for injection and $A>0$ for suction); $\varphi$ is an arbitrary function representing the nature of the unsteadiness in the external stream and has a continuous derivative and $\varphi_{1}$ represents the variation of the wall temperature with time. The subscripts $L, t, d, D, v$ and $V$ denote the longitudinal curvature effect, transverse curvature effect, displacement effect (terms $\sim U_{21}$ ), displacement effect (terms $\sim W_{21}$ ), vorticity interaction effect (terms $\sim \Omega_{z 1}$ ) and vorticity interaction effect (terms $\sim \Omega_{x 1}$ ), respectively. The subscript $w$ denotes conditions at the wall, the subscript $t^{*}$ denotes derivatives with respect to $t^{*}$ and prime denotes derivatives with respect to $\eta$.

We assume that the flow is initially steady and then becomes unsteady for $t^{*}>0$. As mentioned earlier, the steady-state equations are obtained by putting

$\varphi\left(t^{*}\right)=1.0, \quad \varphi_{1}\left(t^{*}\right)=1.0, \quad \varphi_{t^{*}}=0, \quad()_{t^{*}}=0$

in Eqs. (1) - (14) and they are the same as those obtained by Vasantha [5] and Papenfuss [7-8].

The first-order skin-friction coefficients in the $x$ and $z$ directions and the heat-transfer coefficient, in the form of Stanton number $S t$, can be expressed as

$$
\begin{aligned}
& C_{f x 1}=\tau_{w x 1} / \varrho U_{\infty}^{2}=\varepsilon U_{11}^{3 / 2} k_{x 0} x \varphi f^{\prime \prime}(0), \\
& C_{f z 1}=\tau_{w z 1} / \varrho U_{\infty}^{2}=\varepsilon U_{11}^{3 / 2} k_{x 0} z \varphi c g^{\prime \prime}(0), \\
& S t_{1}=-q_{w 1} /\left[\varrho c_{p} U_{\infty}\left(T_{w}-T_{\infty}\right)\right]=\varepsilon U_{11}^{1 / 2} \operatorname{Pr}^{-1} \theta^{\prime}(0)
\end{aligned}
$$

The skin-friction coefficients in the $x$ and $z$ directions and the heat-transfer coefficient, in the form of Stanton number St due to the combined effects of first- and second-order can be expressed as

$$
\begin{aligned}
& C_{f x}=\tau_{w x} / \varrho U_{\infty}^{2}=\varepsilon U_{11}^{3 / 2} k_{x 0} x \\
& \cdot\left\{\varphi f^{\prime \prime}(0)+\varepsilon U_{11}^{-1 / 2} \varphi\left[F_{L}^{\prime \prime}(0)+k F_{t}^{\prime \prime}(0)\right]\right. \\
& +\varepsilon U_{11}^{-1} \varphi\left[U_{21} F^{\prime \prime}{ }_{d}(0)+W_{21} F_{D}^{\prime \prime}(0)\right]+\varepsilon U_{11}^{-3 / 2} \varphi \\
& \left.\cdot\left[\Omega_{z 1} F_{v}^{\prime \prime}(0)+\Omega_{x 1} F_{V}^{\prime \prime}(0)\right]\right\}, \\
& C_{f z}=\tau_{w z} / \varrho U_{\infty}^{2}=\varepsilon U_{11}^{3 / 2} k_{x 0} z c \\
& \cdot\left\{\varphi g^{\prime \prime}(0)+\varepsilon U_{11}^{-1 / 2} \varphi\left[G_{L}^{\prime \prime}(0)+k G_{t}^{\prime \prime}(0)\right]+\varepsilon U_{11}^{-1} \varphi\right. \\
& \cdot\left[U_{21} G_{d}^{\prime \prime}(0)+W_{21} G_{D}^{\prime \prime}(0)\right]+\varepsilon U_{11}^{-3 / 2} \varphi\left[\Omega_{z 1} G_{v}^{\prime \prime}(0)\right. \\
& \left.\left.+\Omega_{x 1} G_{V}^{\prime \prime}(0)\right]\right\}, \\
& \left.S t=-q_{w} / \varrho c_{p} U_{\infty}\left(T_{w}-T_{\infty}\right)\right] \\
& =\varepsilon_{11} U_{11}^{1 / 2} \operatorname{Pr}^{-1}\left\{\theta^{\prime}(0)+\varepsilon U_{11}^{-1 / 2}\left[H_{L}^{\prime}(0)+k H_{t}^{\prime}(0)\right]\right. \\
& +\varepsilon U_{11}^{-1}\left[U_{21} H_{d}^{\prime}(0)+W_{21} H_{D}^{\prime}(0)\right] \\
& \left.+\varepsilon U_{11}^{-3 / 2}\left[\Omega_{z 1} H_{v}^{\prime}(0)+\Omega_{x 1} H_{V}^{\prime}(0)\right]\right\} \text {. }
\end{aligned}
$$

Here $C_{f x}$ and $C_{f z}$ are the skin-friction coefficients in the $x$ and $z$ directions, respectively; $S t$ is the Stanton number representing the heat transfer; $\tau_{w x}$ and $\tau_{w z}$ are the wall shear stresses in the $x$ and $z$ directions, respectively; $q_{w}$ is the rate of heat transfer and $c_{p}$ is the specific heat at a constant pressure. The subscripts 1 and 2 denote the firstand second-order boundary-layer effects, respectively.

\section{Results and discussion}

The set of nonlinear Eq. (1) representing the first-order boundary layer together with boundary conditions (2) for nodal-point flows $(0 \leqq c \leqq 1)$ has been solved by the method of quasilinearization with implicit finite-difference scheme. Then the second-order boundary-layer equations represented by the set of linear Eqs. (3), (5), (7), (9), (11), (13) with boundary conditions (4), (6), (8), (10), (12), (14) have been solved by the method of implicit finitedifference scheme. Due to the reverse nature of the flow in the saddle-point region $(-1 \leqq c<0)$ we have used the method of parametric differentiation in combination with the implicit finite-difference scheme. Since the detailed description of the methods has been given in [14, $17-22]$, it is not presented here. The step sizes $\Delta \eta$ and $\Delta t^{*}$ were optimized and $\Delta \eta=0.01$ and $\Delta t^{*}=0.1$ were used throughout the computation. Further reduction in the step sizes $\Delta \eta$ and $\Delta t^{*}$ changes the results only in the fourth decimal place. The computations have been carried out for various values of the mass transfer parameter $A$, the parameter characterizing the nature of the stagnation point $c$ and the Prandtl number $P r$. The unsteady freestream velocity distributions and the wall temperature distribution considered are given by

$$
\begin{aligned}
\varphi\left(t^{*}\right) & =1+\varepsilon t^{* 2}, \quad \varphi\left(t^{*}\right)=1-\varepsilon t^{* 2}, \quad \varphi\left(t^{*}\right) \\
& =1+\varepsilon_{1} \sin ^{2}\left(\omega^{*} t^{*}\right), \\
\varphi_{1}\left(t^{*}\right) & =1-\varepsilon_{2} t^{*},
\end{aligned}
$$

where $\varepsilon_{0} \varepsilon_{1}$ and $\varepsilon_{2}$ are constants and $\omega^{*}$ is the frequency parameter.

In order to assess the accuracy of our method, we have compared steady-state results with those of Vasantha [5] and Papenfuss [7] and found them in good agreement (Fig. 2).

We assume that the $\Omega_{z 1}, \Omega_{x 1}$ and $U_{21}$ are negative and $0 \leqq \Omega_{z 1}, \quad \Omega_{x 1} \leqq 0.6$ for $-1 \leqq c \leqq 1 \quad[23], \quad U_{21} \cong-0.61$ [24-25]. The value of $\varepsilon$ is taken to be 0.1 . Figures 3-9 show the skin-friction and heat-transfer coefficients due to the first-order boundary layers and due to the combined effect of first- and second-order boundary layers for the case of an accelerating stream $\left(\varphi\left(t^{*}\right)=1+\varepsilon t^{* 2}\right)$. The results for the decelerating $\left(\varphi\left(t^{*}\right)=1-\varepsilon t^{* 2}\right)$ and oscillating $\left(\varphi\left(t^{*}\right)=1+\varepsilon_{1} \sin ^{2}\left(\omega^{*} t^{*}\right)\right)$ streams are given in Figs. 10 and 11, respectively. Figures $12-17$ depict the skin-friction and heat-transfer coefficients due to the longitudinal and transverse curvatures (Figs. 12, 13), boundary-layer displacement (Figs. 14, 15) and vorticity interaction (Figs. 16, 17) for the case $\varphi\left(t^{*}\right)=1+\varepsilon t^{* 2}$. We have not discussed here the results due to the firstorder boundary layers as they are available elsewhere in the literature [26-27].

It has been observed from Figs. 3-11 that the skinfriction coefficients in the $x$ and $z$ directions $\bar{C}_{f x}\left(\bar{C}_{f x}=\right.$ $\left.\left[\varepsilon U_{11}^{3 / 2} k_{x 0} x\right]^{-1} C_{f x}\right)$ and $\bar{C}_{f z}\left(\bar{C}_{f z}=\left[\varepsilon U_{11}^{3 / 2} k_{x 0} z\right]^{-1} C_{f z}\right)$ due to the first- and second-order boundary layers are less than 


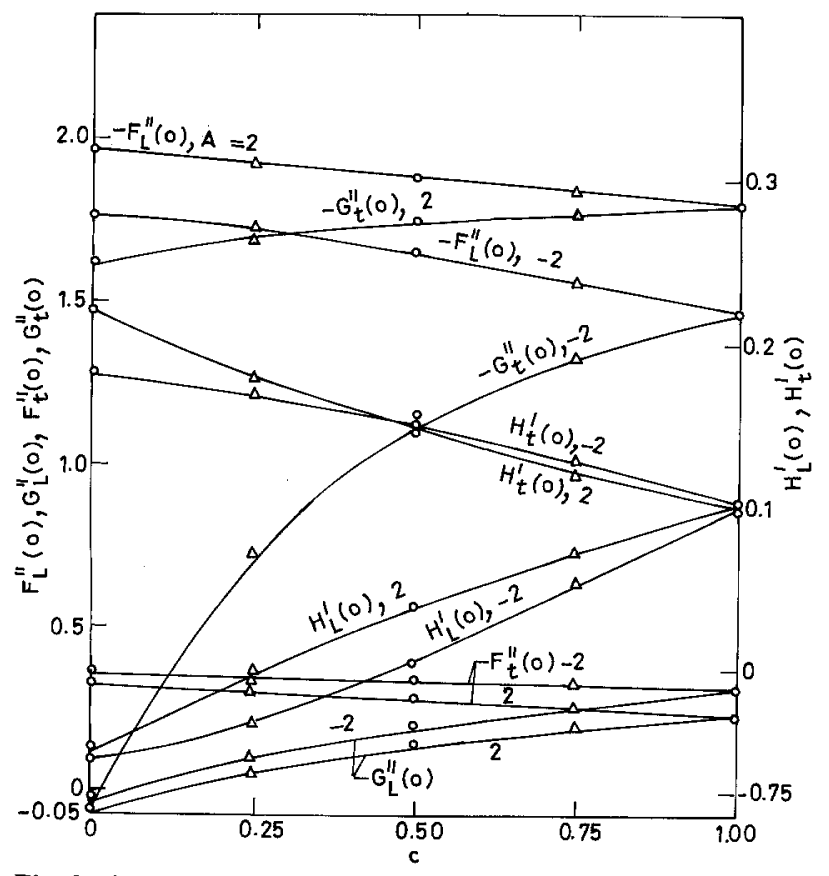

Fig. 2. Skin-friction parameters in the $x$-direction $F_{L}^{\prime \prime}(0)$ and $F_{l}^{\prime \prime}(0)$, skin-friction parameters in the $z$-direction $G_{L}^{\prime \prime}(0)$ and $G_{t}^{\prime \prime}(0)$ and heat-transfer parameters $H_{L}^{\prime}(0)$ and $H_{t}^{\prime}(0)$ for $t^{*}=0$, $\varphi\left(t^{*}\right)=1.0$ and $\varphi_{1}\left(t^{*}\right)=1.0$. - , present solution; 0 , Vasantha; $\triangle$, Papenfuss

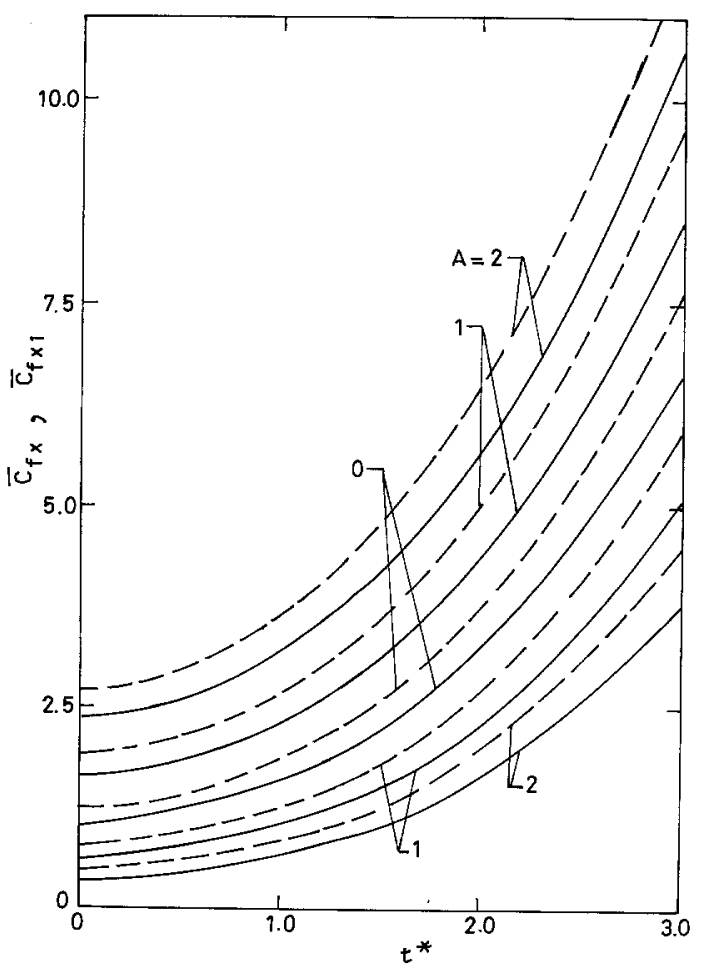

Fig. 3. Skin-friction coefficients in the $x$-direction $\bar{C}_{f x}$ and $\bar{C}_{f x 1}$ for $\varphi\left(t^{*}\right)=1+\varepsilon t^{* 2}, \varphi_{1}\left(t^{*}\right)=1.0, c=0.5, \operatorname{Pr}=0.7$ and $\varepsilon=0.25$.

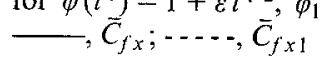

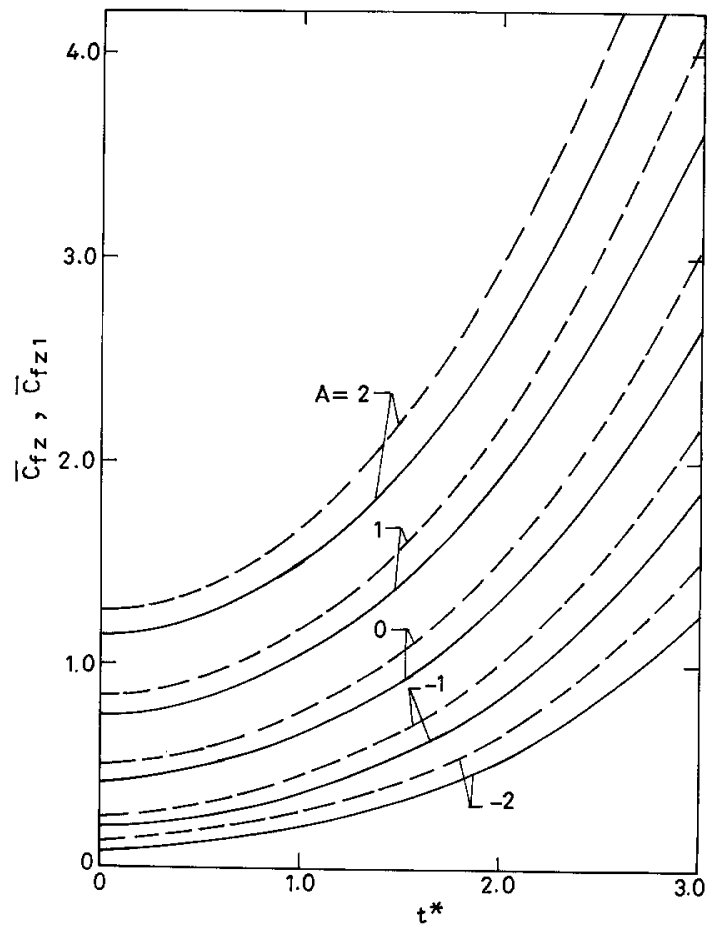

Fig. 4. Skin-friction coefficients in the $z$-direction $\bar{C}_{f z}$ and $\bar{C}_{f z !}$ for $\varphi\left(t^{*}\right)=1+\varepsilon t^{* 2}, \varphi_{1}\left(t^{*}\right)=1.0, c=0.5, P r=0.7$ and $\varepsilon=0.25$. $\longrightarrow, \bar{C}_{f z} ; \cdots, \bar{C}_{f z l}$

the skin-friction coefficients in the $x$ and $z$ directions $\bar{C}_{f x 1}$ and $\bar{C}_{f z 1}$ due to the first-order boundary layers, respectively. This is true for all values of time $t^{*}$, the mass transfer parameter $A$ and the parameter characterizing the nature of the stagnation point $c$. It has also been observed that the second-order effects become more pronounced on $\bar{C}_{f x}$ and $\bar{C}_{f z}$ as $t^{*}$ or $A$ or $\operatorname{Pr}$ increases or $c$ decreases. For all values of $t^{*}, A, c$ and $P r$, the heat-transfer coefficient $\overline{S t}\left(\overline{S t}=\left[\varepsilon U_{11}^{1 / 2} \mathrm{Pr}^{-1}\right]^{-1} S t\right)$ due to the combined effects of first- and second-order is more than the firstorder heat-transfer coefficient $\overline{S t}_{1}$. The coefficient $\overline{S t}$ increases less than $\overline{S t}_{1}$ as $t^{*}, A$ and $P r$ increase or $c$ decreases. The variations of skin friction and heat transfer with time $t^{*}$ are significant for large times.

Figures 3-5 depict the effect of the mass transfer parameter $(A)$ on the skin-friction and heat-transfer coefficients $\left(\bar{C}_{f x}, \bar{C}_{f z}, \overline{S t}\right)$ with $t^{*}$. It is evident from these figures that for all values of the mass transfer parameter $A$, the skin-friction coefficient in the $x$-direction $\bar{C}_{f x}$, skinfriction coefficient in the $z$-direction $\bar{C}_{f z}$ and heat-transfer coefficient $\overline{S t}$ increase as $t^{*}$ increases. Injection $(A<0)$ decreases the skin-friction and heat-transfer coefficients and suction $(A>0)$ does the reverse. This is due to thickening of both velocity and thermal boundary layers with injection which causes deceleration in the fluid with the result that both skin friction and heat transfer decrease 


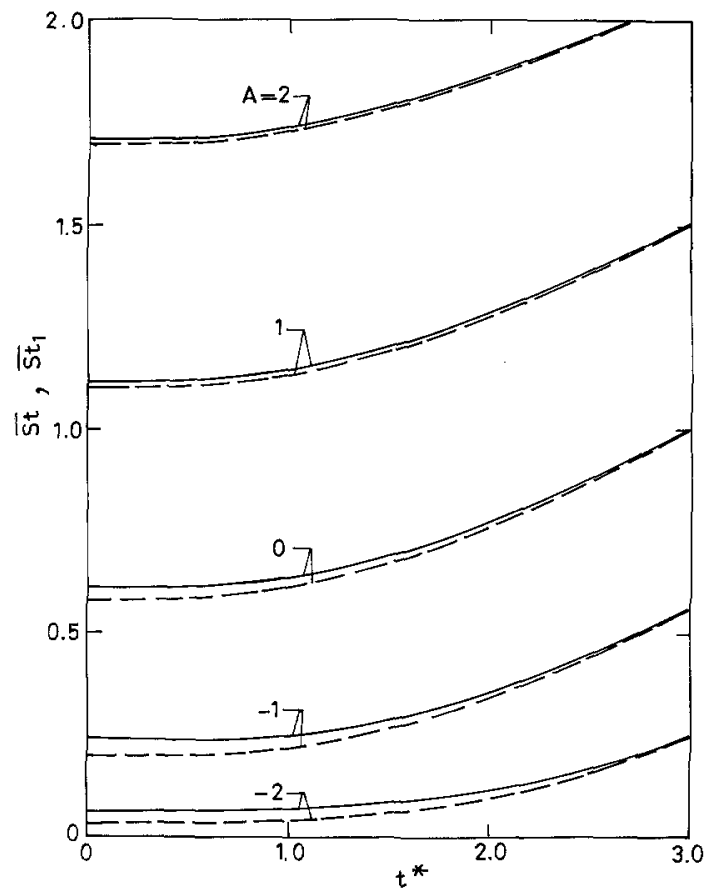

Fig. 5. Heat-transfer coefficients $\overline{S t}$ and $\overline{S t}_{1}$ for $\varphi\left(t^{*}\right)=1+\varepsilon t^{* 2}$, $\varphi_{1}\left(t^{*}\right)=1.0, c=0.5, P r=0.7$ and $\varepsilon=0.25$. -,$\overline{S t} ; \cdots,-, \overline{S t_{1}}$

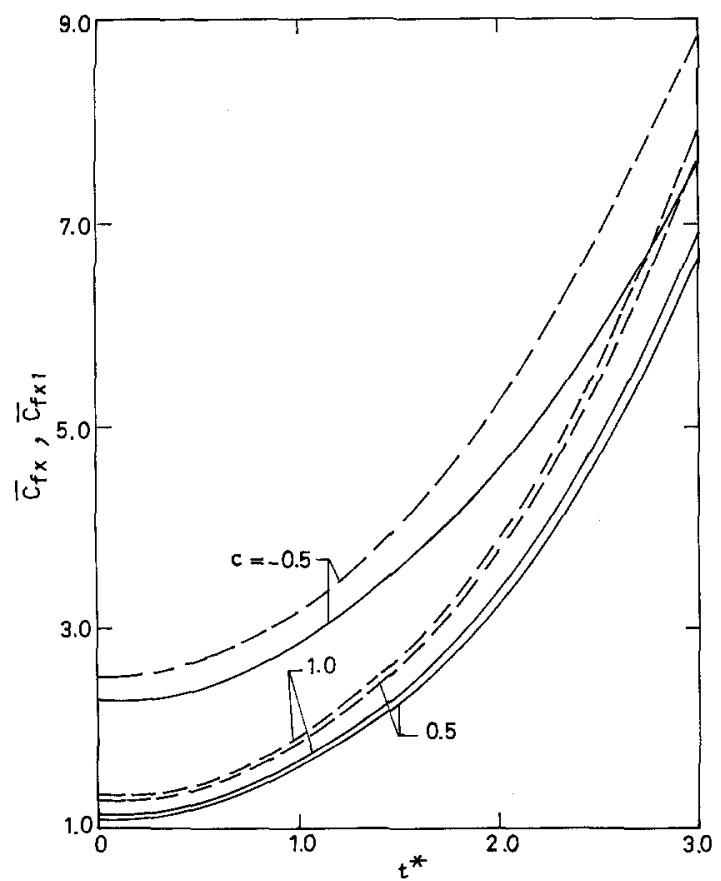

Fig. 6. Skin-friction coefficients in the $x$-direction $\bar{C}_{f x}$ and $\bar{C}_{f x 1}$ for $\varphi\left(t^{*}\right)=1+\varepsilon t^{* 2}, \varphi_{1}\left(t^{*}\right)=1-\varepsilon_{2} t^{*}, A=0.0, \operatorname{Pr}=0.7, \varepsilon=0.25$ and $\varepsilon_{2}=0.1 . \longleftarrow, \bar{C}_{f x}, \varphi_{1}\left(t^{*}\right)=1.0 ; \cdots,-\bar{C}_{f x l}, \varphi_{1}\left(t^{*}\right)=1.0$

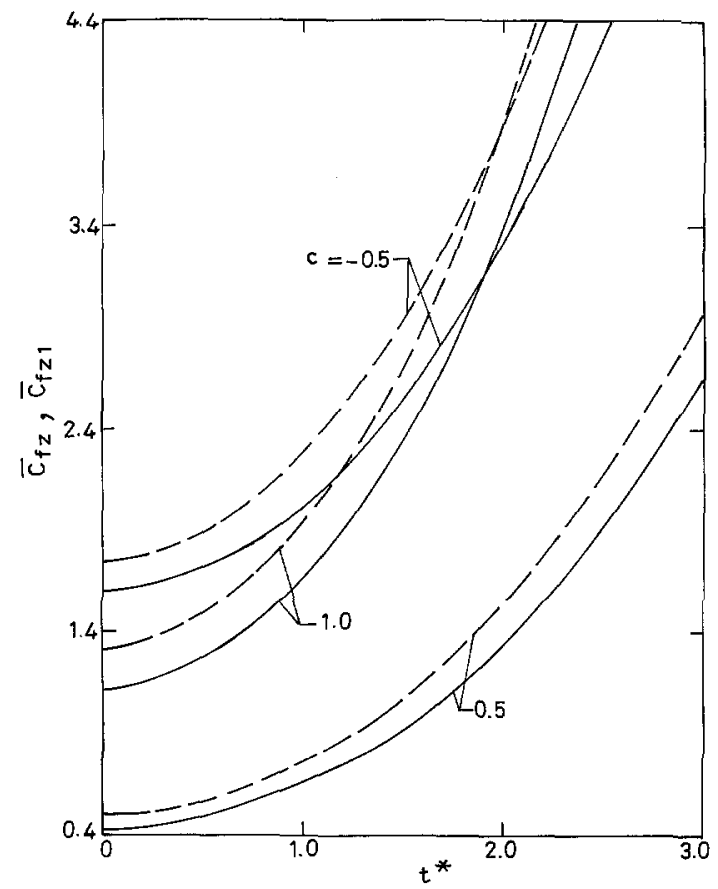

Fig. 7. Skin-friction coefficients in the $z$-direction $\bar{C}_{f z}$ and $\bar{C}_{f z 1}$ for $\varphi\left(t^{*}\right)=1+\varepsilon t^{* 2}, \varphi_{1}\left(t^{*}\right)=1-\varepsilon_{2} t^{*}, A=0.0, \operatorname{Pr}=0.7, \varepsilon=0.25$ and $\varepsilon_{2}=0.1 .-, \bar{C}_{f z}, \varphi_{1}\left(t^{*}\right)=1.0 ; \cdots, \bar{C}_{f z 1}, \varphi_{1}\left(t^{*}\right)=1.0$

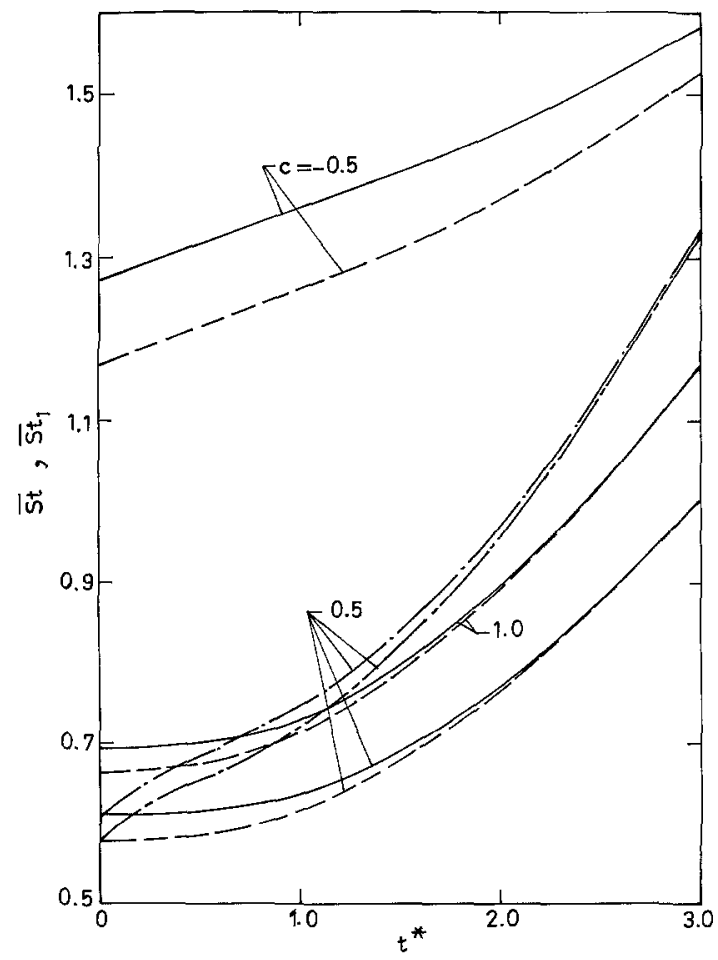

Fig. 8. Heat-transfer coefficients $\overline{S t}$ and $\overline{S t}_{1}$ for $\varphi\left(t^{*}\right)=1+\varepsilon t^{* 2}$, $\varphi_{1}\left(t^{*}\right)=1-\varepsilon_{2} t^{*}, A=0.0, \operatorname{Pr}=0.7, \varepsilon=0.25$ and $\varepsilon_{2}=0.1$. $S t, \varphi_{1}\left(t^{*}\right)=1.0 ; \cdots .-, \overline{S t}_{1}, \varphi_{1}\left(t^{*}\right)=1.0 ;-\cdot-, \overline{S t}, \varphi_{1}\left(t^{*}\right)=$ $1-\varepsilon_{2} t^{*} ;--\longrightarrow, \overline{S t}_{1}, \varphi_{1}\left(t^{*}\right)=1-\varepsilon_{2} t^{*}$ 
with injection. For suction, the opposite trend is observed. It has also been observed from these figures that the effect of the parameter $A$ on $\bar{C}_{f x}, \bar{C}_{f z}$ and $\overline{S t}$ increases with $t^{*}$. The effect of suction is more pronounced on $\bar{C}_{f x}, \bar{C}_{f z}$ and $\overline{S t}$ than the effect of injection.

The skin-friction and heat-transfer coefficients $\bar{C}_{f x}, \bar{C}_{f z}$ and $\overline{S t}$ for different values of the parameter $c$ characterizing the nature of the stagnation point are shown in Figs. 6-8. Figure 9 depicts the effect of the Prandtl number $P r$ on the heat-transfer coefficient $\overline{S t}$. These figures show that the coefficients $\bar{C}_{f x}, \bar{C}_{f z}$ and $\overline{S t}$ increase at $t^{*}$ increases. This is true for all values of the parameter $c$. It is also clear from these figures that the coefficients $\bar{C}_{f x}, \bar{C}_{f z}$ and $\overline{S t}$ decrease as $c$ decreases until at some negative $c$ then $\bar{C}_{f z}$ is reversed and $\bar{C}_{f x}$ and $\overline{S t}$ begin to increase as $c$ decreases. Similar trend has also been observed in the case of first-order boundary layers [26-27]. The effect of the parameter $c$ on $\bar{C}_{f x}, \bar{C}_{f z}$ and $\overline{S t}$ increases as $t *$ increases. It has also been observed that the variation of the wall temperature with time has its effect only on the heat-transfer coefficient $\overline{S t}$. The coefficient $\overline{S t}$ increases with $t^{*}$ as the wall temperature decreases with $t^{*}$ and the effect of the variation of the wall temperature with time decreases as $t^{*}$ increases. The heat-transfer coefficient $\overline{S t}$ increases as $t^{*}$ or Prandtl number $P r$ increases. $\overline{S t}$ increases more with $t^{*}$ for small value of the Prandtl number $P r$ and increases less for large value of $\operatorname{Pr}$ (Fig. 9).

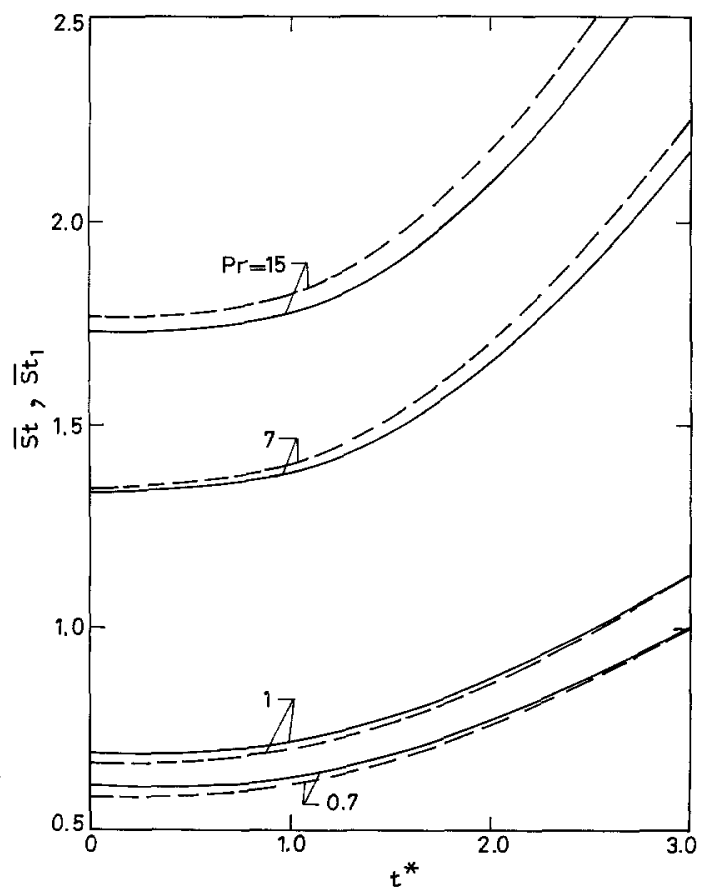

Fig. 9. Heat-transfer coefficients $\overline{S t}$ and $\overline{S t}_{1}$ for $\varphi\left(t^{*}\right)=1+\varepsilon t^{* 2}$, $\varphi_{1}\left(t^{*}\right)=1.0, A=0.0, c=0.5$ and $\varepsilon=0.25$. $-\overline{S t} ;-\cdots, \overline{S t}_{1}$

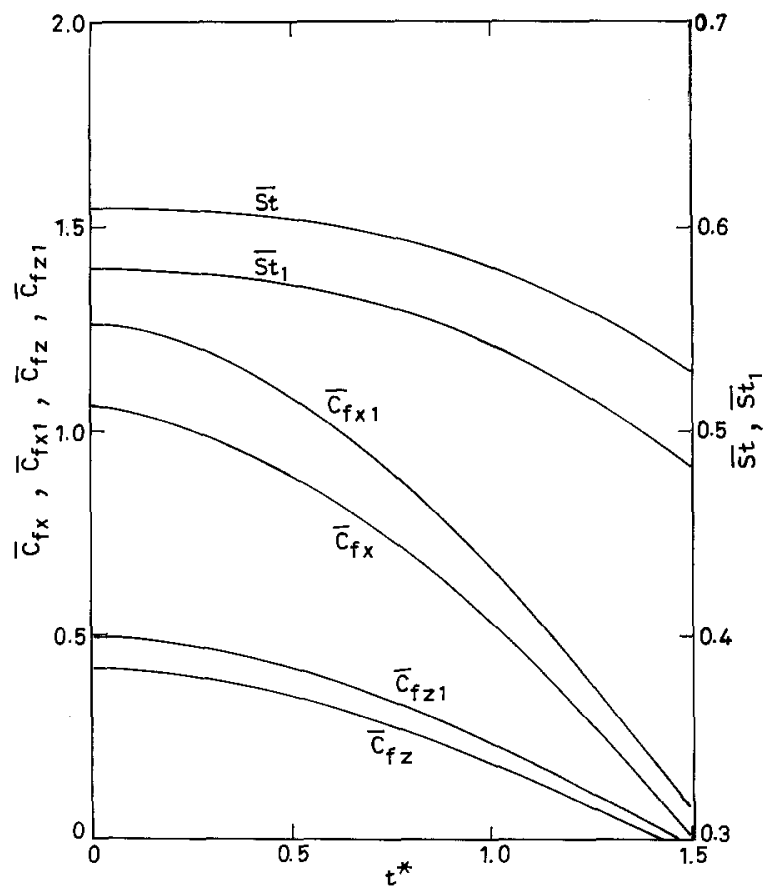

Fig. 10. Skin-friction coefficients in the $x$-direction $\bar{C}_{f x}$ and $\bar{C}_{f x l}$, skin-friction coefficients in the $z$-direction $\bar{C}_{f z}$ and $\bar{C}_{f z 1}$ and heattransfer coefficients $\overline{S t}$ and $\overline{S t}$ for $\varphi\left(t^{*}\right)=1-\varepsilon t^{* 2}, \varphi_{1}\left(t^{*}\right)=1.0$, $A=0.0, c=0.5, \operatorname{Pr}=0.7$ and $\varepsilon=0.25$

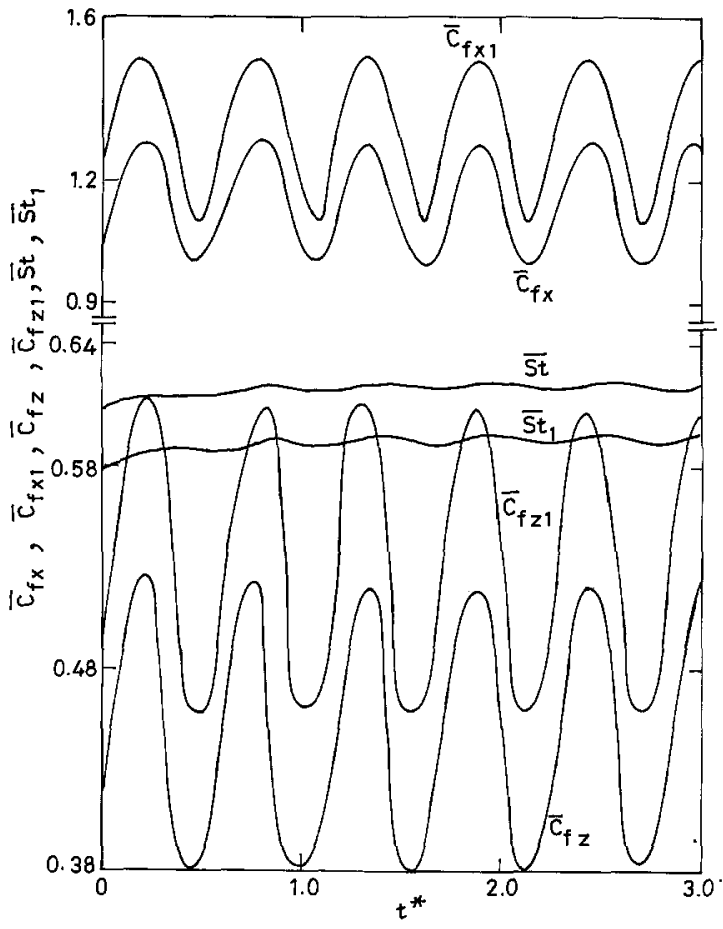

Fig. 11. Skin-friction coefficients in the $x$-direction $\bar{C}_{f x}$ and $\bar{C}_{f x 1}$, skin-friction coefficients in the $z$-direction $\bar{C}_{f z}$ and $\bar{C}_{f z 1}$ and heattransfer coefficients $\overline{S t}$ and $\overline{S t}_{1}$ for $\varphi\left(t^{*}\right)=1+\varepsilon_{1} \sin ^{2}\left(\omega^{*} t^{*}\right)$, $\varphi_{1}\left(t^{*}\right)=1.0, A=0.0, c=0.5, \operatorname{Pr}=0.7, \varepsilon_{1}=0.1$ and $\omega^{*}=5.6$ 


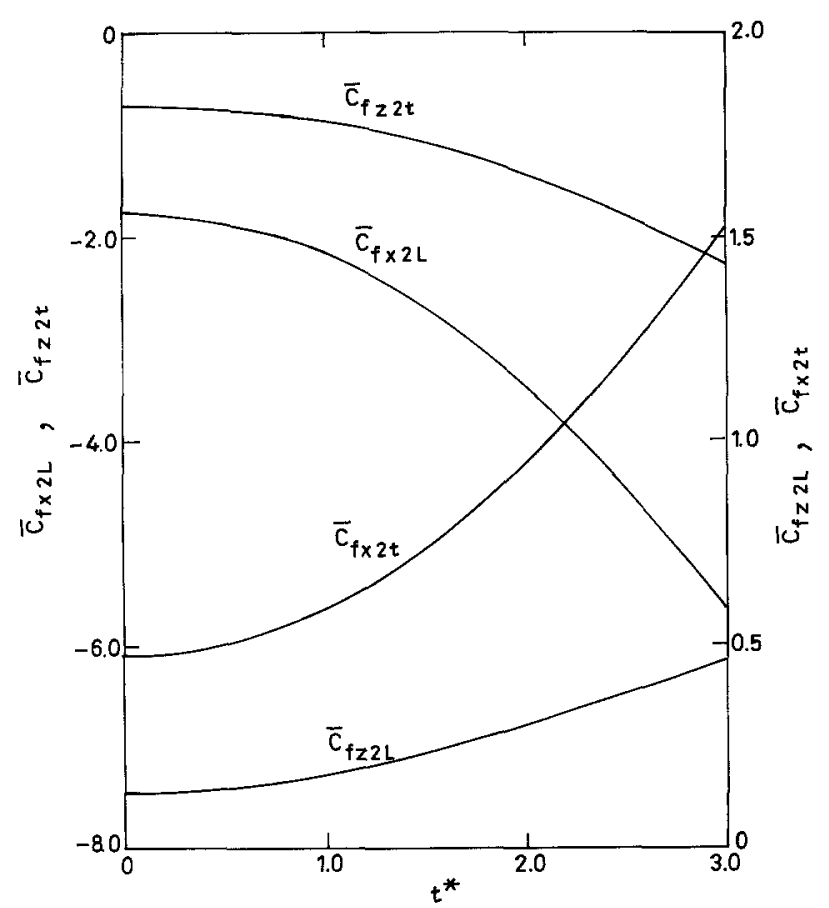

Fig. 12. Skin-friction coefficients in the $x$-direction $\bar{C}_{f \times 2 L}$ and $\bar{C}_{f \times 2 t}$ and skin-friction coefficients in the $z$-direction $\bar{C}_{f z 2 L}$ and $\bar{C}_{f z 2 t}$ for $\varphi\left(t^{*}\right)=1+\varepsilon t^{* 2}, \varphi_{1}\left(t^{*}\right)=1.0, A=0.0, c=0.5, \operatorname{Pr}=0.7$ and $\varepsilon=0.25$ (longitudinal and transverse curvatures)

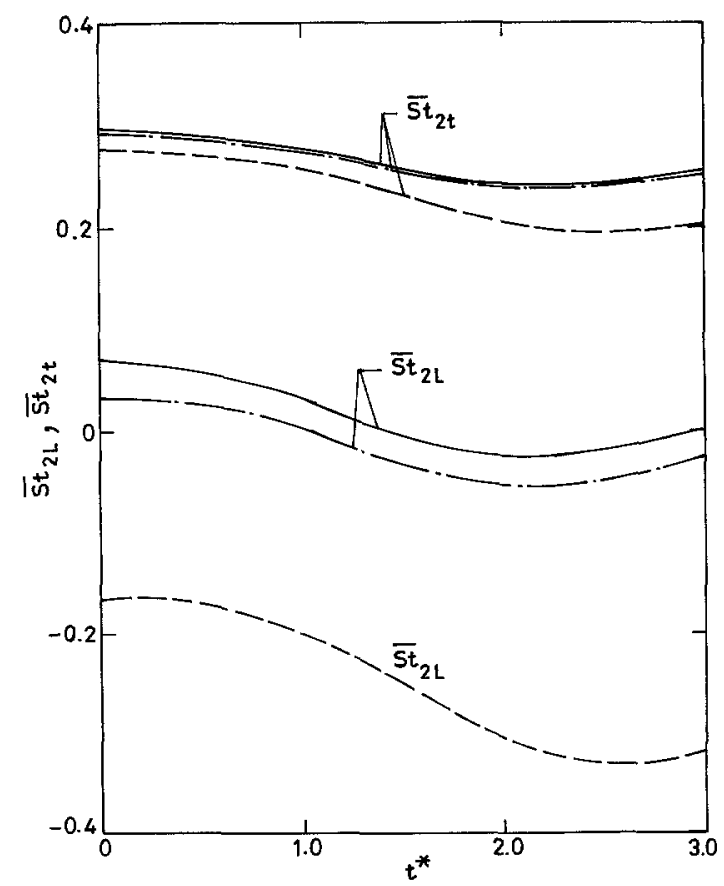

Fig. 13. Heat-transfer coefficients $\overline{S t}_{2 L}$ and $\overline{S t}_{2 t}$ for $\varphi\left(t^{*}\right)=$ $1+\varepsilon t^{* 2}, \quad \varphi_{1}\left(t^{*}\right)=1.0, \quad A=0.0, \quad c=0.5$ and $\varepsilon=0.25$. $P r=0.7 ;-.+P r=1.0 ; \cdots, P r=7.0$ (longitudinal and transverse curvatures)

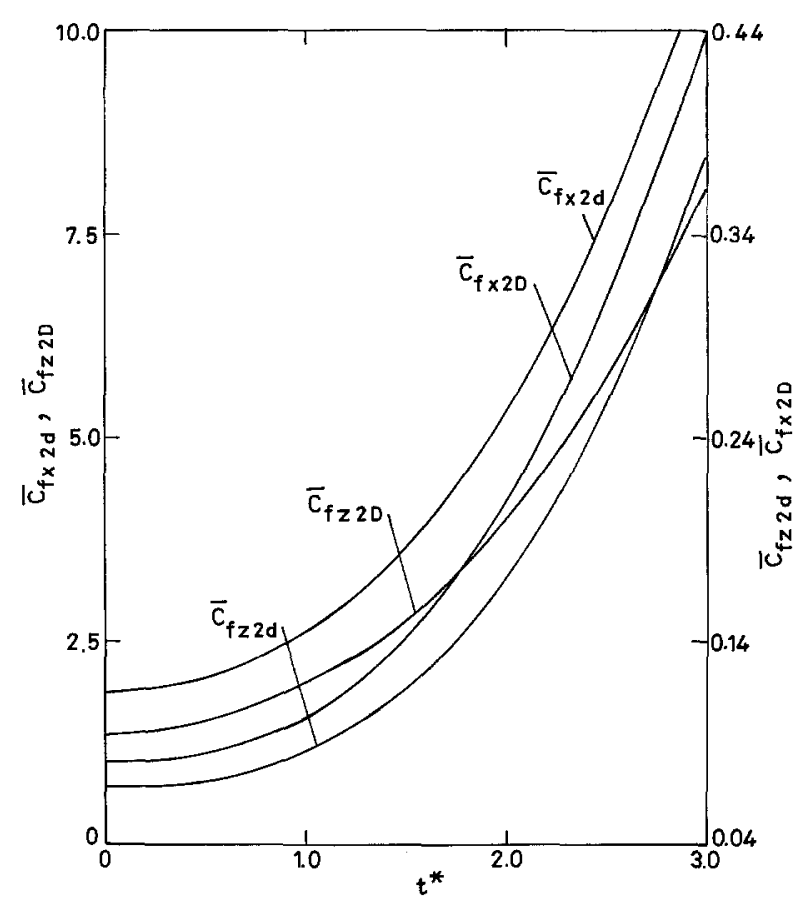

Fig. 14. Skin-friction coefficients in the $x$-direction $\bar{C}_{f \times 2 d}, \bar{C}_{f \times 2 D}$ and skin-friction coefficients in the $z$-direction $\bar{C}_{f z 2 d}$ and $\bar{C}_{f z 2 D}$ for $\varphi\left(t^{*}\right)=1+\varepsilon t^{* 2}, \varphi_{1}\left(t^{*}\right)=1.0, A=0.0, c=0.5, P r=0.7$ and $\varepsilon=0.25$ (displacement $\sim U_{21}$ and $W_{21}$ )

Figures 10 and 11 show the skin-friction and heat-transfer coefficients for the decelerating $\left(\varphi\left(t^{*}\right)=1-\varepsilon t^{* 2}\right)$ and oscillating $\left(\varphi\left(t^{*}\right)=1+\varepsilon_{1} \sin ^{2}\left(\omega^{*} t^{*}\right)\right)$ free stream. It has been observed from Fig. 10 that the skin-friction and heat-transfer coefficients $\bar{C}_{f x}, \bar{C}_{f z}$ and $\overline{S t}$ decrease with $t^{*}$ when the free-stream decelerates with time $\left(\varphi\left(t^{*}\right)=\right.$ $1-\varepsilon t^{* 2}$ ). This behaviour is true for all values of the parameters $A, c$ and $P r$. In the case of oscillating free stream $\varphi\left(t^{*}\right)=1+\varepsilon_{1} \sin ^{2}\left(\omega^{*} t^{*}\right)$, the coefficients $\bar{C}_{f x}$, $\bar{C}_{f z}$ and $\overline{S t}$ oscillate with $t^{*}$. It has also been observed that $\bar{C}_{f x}$ oscillates more with $t^{*}$ and compared to $\bar{C}_{f z}$ and St (Fig. 11).

The skin-friction and heat-transfer coefficients due to longitudinal and transverse curvatures are depicted in Figs. 12-13. Figures 14-15 show displacement effects (terms $\sim U_{21}$ and $W_{21}$ ) on the skin-friction and heattransfer coefficients. The effects of vorticity interaction (terms $\sim \Omega_{z_{1}}$ and $\Omega_{x_{1}}$ ) on the skin-friction and heattransfer is displayed in Figs. 16-17. It has been observed that the skin-friction coefficient in the $x$ direction due to longitudinal curvature $\left(\bar{C}_{f \times 2 L}\right)$ and skin-friction coefficient in the $z$ direction due to transverse curvature $\left(\bar{C}_{f z 2 t}\right)$ decrease as $t^{*}$ increases whereas the skin-friction coefficient in the $z$ direction due to longitudinal curvature $\left(\bar{C}_{f z 2 L}\right)$ and skin-friction coefficient in the $x$ direction due 


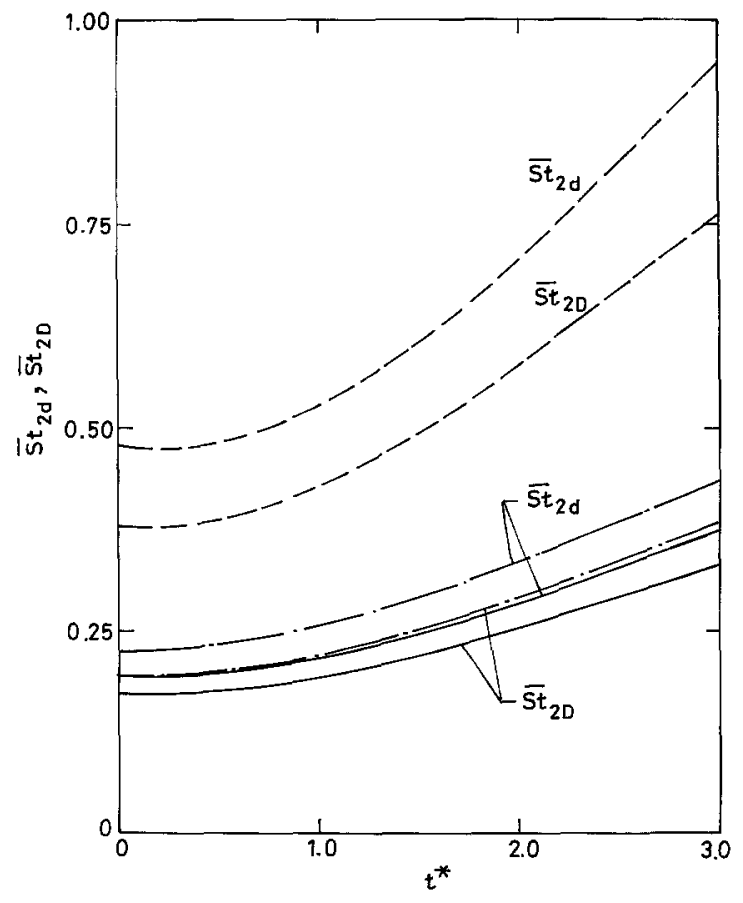

Fig. 15. Heat-transfer coefficients $\overline{S t}_{2 d}$ and $\overline{S t}_{2 D}$ for $\varphi\left(t^{*}\right)=$ $1+\varepsilon t^{* 2}, \quad \varphi_{1}\left(t^{*}\right)=1.0, \quad A=0.0, \quad c=0.5$ and $\varepsilon=0.25$. $\operatorname{Pr}=0.7 ;-1-\operatorname{Pr}=1.0 ; \cdots, P r=7.0$ (displacement $\sim U_{21}$ and $\left.W_{21}\right)$

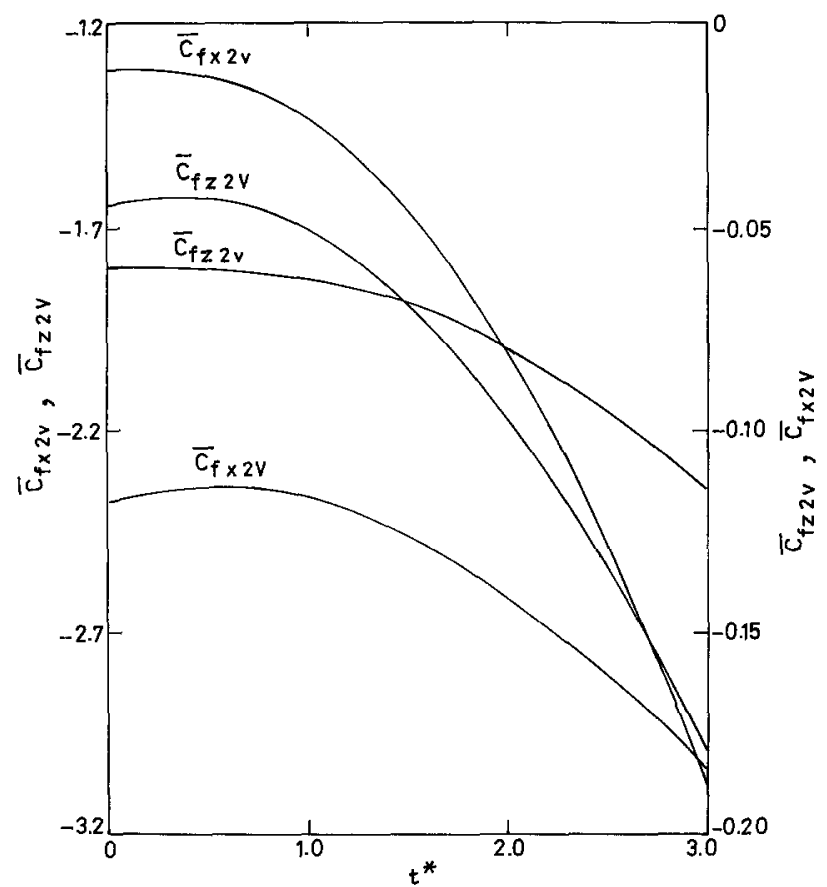

Fig. 16. Skin-friction coefficients in the $x$-direction $\bar{C}_{f \times 2 v}$ and $\bar{C}_{f \times 2 v}$ and skin-friction coefficients in the $z$-direction $\bar{C}_{f z 2 v}$ and $\vec{C}_{f z 2 v}$ for $\varphi\left(t^{*}\right)=1+\varepsilon t^{* 2}, \varphi_{1}\left(t^{*}\right)=1.0, A=0.0, c=0.5, P_{r}=0.7$ and $\varepsilon=0.25$ (vorticity interaction $\sim \Omega_{z 1}$ and $\Omega_{x 1}$ )

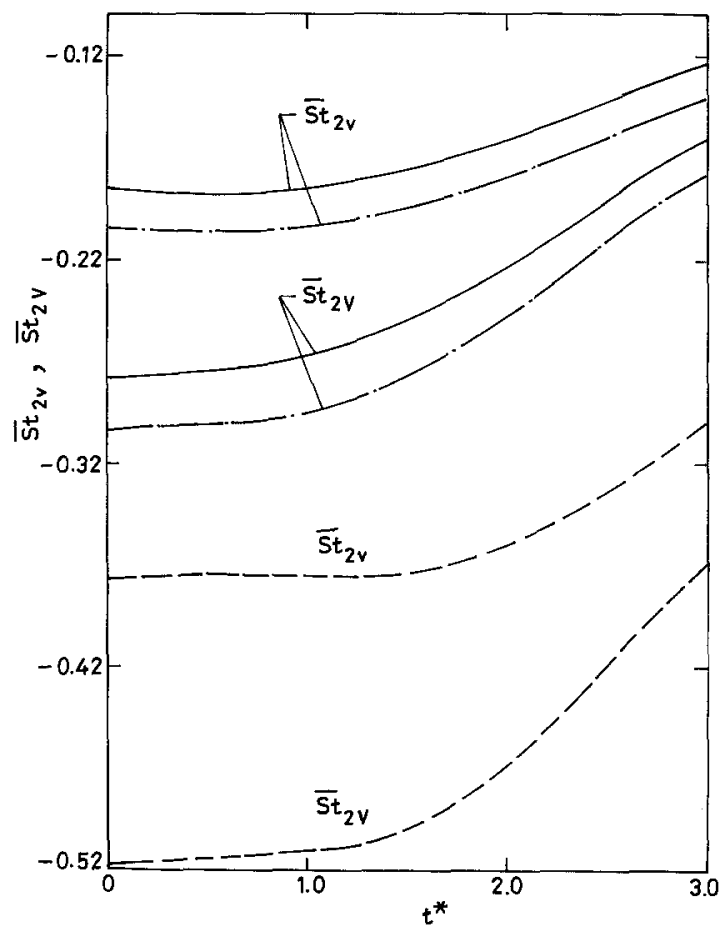

Fig. 17. Heat-transfer coefficients $\overline{S t}_{2,}$ and $\overline{S t}_{2 V}$ for $\varphi\left(t^{*}\right)=$ $1+\varepsilon t^{* 2}, \quad \varphi_{1}\left(t^{*}\right)=1.0, \quad A=0.0, \quad c=0.5$ and $\varepsilon=0.25$. $\operatorname{Pr}=0.7 ;-\cdot \longrightarrow, \operatorname{Pr}=1.0 ; \cdots,-\cdots, \operatorname{Pr}=7.0$ (vorticity interaction $\sim \Omega_{z 1}$ and $\Omega_{x 1}$ )

to transverse curvature $\left(\bar{C}_{f \times 2 t}\right)$ increase with $t^{*}$ (Fig. 12). The skin-friction coefficients in the $x$ and $z$ directions due to displacement $\bar{C}_{f x 2 d}, \bar{C}_{f z 2 d}$ (terms $\sim U_{21}$ ), $\bar{C}_{f x 2 D}, \bar{C}_{f z 2 D}$ (terms $\sim W_{21}$ ) increase as $t^{*}$ increases (Fig. 14). As $t^{*}$ increases, the skin-friction coefficients in the $x$ and $z$ directions due to vorticity interaction $\bar{C}_{f x 2 v}, \bar{C}_{f z 2 v}, \bar{C}_{f x 2 \mathrm{~V}}$ and $\bar{C}_{f z 2 V}$ (terms $\sim \Omega_{z 1}$ and $\Omega_{x 1}$ ) decrease.

It has been observed from Figs. 13, 15 and 17 that for all values of the Prandtl number $P r$, the heat-transfer coefficients due to longitudinal and transverse curvatures $\left(\overline{S t}_{2 L}\right.$ and $\left.\overline{S t}_{2 t}\right)$ first decrease and then increase as $t^{*}$ increases whereas the heat-transfer coefficients due to displacement (terms $\sim U_{21}$ and $\left.W_{21}\right)\left(\overline{S t}_{2 d}\right.$ and $\overline{S t}_{2 D}$ ) and vorticity interaction (terms $\sim \Omega_{z 1}$ and $\left.\Omega_{x 1}\right)\left(\overline{S t}_{2 v}\right.$ and $\overline{S t}_{2 v}$ ) increase with $t^{*}$. It has also been observed from these figures that the heat-transfer coefficients $\overline{S t}_{2 L}, \overline{S t}_{2 t}, \overline{S t}_{2 v}$ and $\overline{S t}_{2 V}$ decrease as $\mathrm{Pr}$ increases but $\overline{S t}_{2 d}$ and $\overline{S t}_{2 D}$ increase with it. This behaviour is true for all values of $t^{*}$. As $t^{*}$ increases, the effect of $P r$ is more pronounced on $\overline{S t}_{2 L}, \overline{S t}_{2 t}, \overline{S t}_{2 d}$ and $\overline{S t}_{2 D}$ whereas its effect becomes less on $\overline{S t}_{2 v}$ and $\overline{S t}_{2 V}$.

\section{Conclusions}

The partial differential equations governing the secondorder boundary layers for the unsteady three-dimensional 
stagnation point flow have been derived for the first time. The results indicate that the skin friction and heat transfer are strongly affected by the unsteady free-stream velocity distributions, the nature of the stagnation point and the mass transfer parameter. The heat transfer is also affected by the Prandtl number and the variation of the wall temperature with time. The second-order effects reduce the skin friction and increase the heat transfer. The injection decreases the skin-friction and heat transfer whereas the suction has the opposite trend.

\section{Acknowledgements}

The author wishes to thank Prof. G. Nath for many suggestions.

\section{References}

1. Van Dyke, M.: Higher-order boundary-layer theory. Ann. Rev. Fluid Mech. 1 (1969) 265-292

2. Gersten, K.; Gross, J. F.: Higher-order boundary-layer theory. Fluid Dyn. Trans. 7 (1976) 7-36

3. Afzal, N.; Rizvi, S. M. A.: Second-order unsteady stagnationpoint boundary-layer solutions. AIAA J. 15 (1977) $1051-1053$

4. Arunachalam, M.; Rajappa, N. R.: Unsteady boundary layer on a two dimensional or axisymmetric body with higherorder effects. Z. Angew. Math. Mech. 60 (1980) 147-152

5. Vasantha, R.: Numerical studies of laminar boundary layer flow problems. Ph.D. Thesis, Indian Institute of Science 1984

6. Vasantha, R.; Nath, G.: Unsteady compressible second-order boundary layers at the stagnation point of two-dimensional and axisymmetric bodies. Wärme- und Stoffübertrag. 20 (1986) 273-281

7. Papenfuss, H. D.: Die Grenzschichteffekte 2-Ordnung bei der kompressiblen dreidimensionalen Staupunkt-Strömung. Diss. Ruhr-Universität 1975

8. Papenfuss, H. D.: Higher-order solutions for incompressible, three-dimensional boundary-layer flow at the stagnation point of a general body. Arch. Mech. 26 (1974) 981-994

9. Papenfuss, H. D.: The second-order boundary-layer effects for the compressible three-dimensional stagnation-point flow. J. de Mech. 16 (1977) 705-732

10. Papenfuss, H. D.: Mass transfer effects on the three-dimensional second-order boundary-layer flow at the stagnation point of blunt bodies. Mech. Res. Commun. 1 (1974) 285-290

11. Papenfuss, H. D.: The second-order boundary-layer effects at the three-dimensional stagnation point with strong suction or blowing. Z. Flugwiss. Weltraumforsch. 1 (1977) 87-96
12. Gersten, K. Papenfuss, H. D.; Gross, J. F.: Influence of the Prandtl number on second-order heat transfer due to surface curvature at a three-dimensional stagnation point. Int. J. Heat Mass Transfer 21 (1978) 275-284

13. Dwoyer, D. L.; Lewis, C. H.; Gogineni, P. R.: Surface curvature effects on three-dimensional blunt-body boundary layers. AIAA J. 17 (1979) 133-134

14. Krishnaswamy, R.: A numerical study of laminar compressible boundary-layer problems. Ph.D. Thesis, Indian Institute of Science 1980

15. Krishnaswamy, R.; Nath, G.: Compressible second-order boundary layers for three-dimensional stagnation point flows with mass transfer. Int. J. Engng. Sci. 20 (1982) $1221-1233$

16. Kumari, M.: Unsteady laminar incompressible second-order boundary-layer flow at a three-dimensional stagnation point. Acta Mechanica (In press)

17. Libby, P. A.: Heat and mass transfer at a general threedimensional stagnation point. AIAA J. 5 (1967) 505-517

18. Inouye, K.; Tate, A.: Finite-difference version of quasilinearization applied to boundary-layer equations. AIAA J. 12 (1974) $558-560$

19. Liu, T. M.; Chiu, H. H.: Fast and stable numerical method for boundary-layer flow with massive blowing. AIAA J. 14 (1976) $114-116$

20. Rubbert, P. E.: Analysis of transonic flow by means of parametric differentiation. Ph.D. Thesis, M.I.T. 1965

21. Rubbert, P. E.; Landahl, M. T.: Solution of nonlinear flow problems through parametric differentiation. Phys. Fluids 10 (1967) $831-835$

22. Tan, C. W.; Dibiano, R.: A parametric study of FalknerSkan problem with mass transfer. AIAA J. 10 (1972) 923-925

23. Van Dyke, M.: Higher approximations in boundary-layer theory, Part 2: Application to leading edges. J. Fluid Mech. 14 (1962) $481-495$

24. Van Dyke, M.: Higher approximations in boundary-layer theory, Part 3: Parabola in uniform stream. J. Fluid Mech. 19 (1964) $145-159$

25. Devan, L.: Second-order incompressible laminar boundary layer development on a two-dimensional semi-infinite body. Doctoral Dissertation, University of California 1964

26. Kumari, M.: Investigation of laminar boundary-layer flows using finite-difference method. Ph.D. Thesis, Indian Institute of Science 1980

27. Kumari, M.; Nath, G.: Unsteady incompressible three-dimensional asymmetric stagnation-point boundary layers. Trans. ASME, J. Appl. Mech. 47 (1980) 241-246

Dr. Mahesh Kumari

Department of Applied Mathematics

Indian Institute of Science

Bangalore-560012, India

Received September 8, 1986 